\title{
Application of decision analytical models to diabetes in low- and middle-income countries: A systematic review
}

\author{
Eunice Twumwaa Tagoe ( $\nabla$ eunice.adwubi@strath.ac.uk) \\ University of Strathclyde \\ Justice Nonvignon \\ University of Ghana \\ Robert Van Der Meer \\ University of Strathclyde \\ Itamar Megiddo \\ University of Strathclyde
}

\section{Research Article}

Keywords: Decision analytical modelling, diabetes interventions, economic evaluation, simulations, cost-effectiveness

Posted Date: February 23rd, 2022

DOI: https://doi.org/10.21203/rs.3.rs-1216798/v1

License: (c) (i) This work is licensed under a Creative Commons Attribution 4.0 International License. Read Full License 


\section{Abstract}

Background: Decision analytical models (DAMs) are used to develop an evidence base that is used in impact and health economic evaluations, including to evaluate interventions to improve diabetes care and health service-an increasingly important area in low- and middle-income countries (LMICs), where the disease burden is high, health systems are weak, and resources are constrained. Compared with large-scale real-life randomised control trials and cohort studies, DAMs can produce evidence of the health and economic benefits of interventions in an affordable and timely manner, while overcoming ethical issues, by using mathematical and logical relationships to abstract vital aspects of reality/systems for analysis.

This study examines how DAMs-in particular, Markov, system dynamic, agent-based, discrete event simulation and hybrid models-have been applied to investigate non-pharmaceutical (NP) policy interventions and how to advance their adoption to diabetes research in LMICs.

Methods: We conducted a systematic search of peer-reviewed articles published in English between 2000 and 2020 in PubMed, Cochrane and the reference list of reviewed articles. Articles were summarised and appraised based on publication details, model design and processes, modelled interventions, and model limitations.

Results: Thirteen studies were included (six Markov, six microsimulation and one agent-based model), most of which modelled interventions in Asian sub-population. Except for one study (which examined tax increment), all studies assessed interventions within the health sector. Seven studies reported health and economic outcomes and the rest reported health outcomes only. Twelve studies reported on uncertainty analysis. Almost half of the studies did not report on model validation, whereas two studies combined multiple validation techniques to increase confidence in models. Four studies modelled policy interventions among diabetes patients; the rest concentrated on at-risk populations. All studies reported limitations with obtaining sufficient data for modelling.

Conclusions: This review summarises the application of DAMs to NP diabetes interventions in LMICs. Our purpose is to identify gaps in their adoption and advance their appropriate use for assessing NP policies intervention aimed at controlling diabetes. Our study recommends that LMICs should leverage the usefulness of DAMs to support economic evaluation of population-wide NP policy interventions, particularly fiscal policies, to control diabetes.

\subsection{Background}

Diabetes burden is quickly rising globally, especially in low- and middle-income countries (LMICs). In 2021, about 537 million people worldwide lived with diabetes worldwide, an addition of 70 million people since 2019 (1).

The International Diabetes Federation estimated that the number will increase by 46\%, i.e., 783 million people by 2045 (1). This projection may be an underestimate considering the unintended effect of control strategies associated with multiple waves of COVID-19 on diabetes risk distribution, for example, increased stress and low physical activity levels due to lockdown (2). About $79 \%$ of persons with diabetes live in LMICs, especially in Africa, where the largest percentage increase globally is projected to occur in 2045 due to economic development (1). Despite the relatively fast-growing diabetes burden in LMICs, their total health expenditure on diabetes remains lower than in high-income countries (HICs) because of resource constraints and less priority given to chronic diseases. Less than one-third of health expenditure in LMICs is spent on chronic diseases in general, whereas HICs spend more (3).

Diabetes is expensive to manage for individuals, health systems and governments. LMICs may pay more for treatment due to excessive mark-ups, tariffs, and import taxes. Even where drug pricing regulations exist - e.g., China, Indonesia and India - medicine prices remain high (4). Health systems in LMICs, particularly African countries, are less resourced 
to manage the burden of both infectious and chronic diseases (5). Few trained providers, inequitably distributed medical equipment and suboptimal referral systems continue to obstruct optimal health service delivery in LMICs (5). Medicines comprise about one-third of diabetes management costs in LMICs, and the price of medicines varies significantly $(4,5)$. When originator brand products are prescribed instead of cheap biosimilars, the treatment cost is higher (6). Indirect diabetes costs are also high, comprising the cost of productive hours lost to hospital attendance, care provided by family members and premature death. The COVID-19 pandemic has further worsened LMICs health systems' capability to manage chronic diseases, creating an urgent need for cost-effective interventions to build resilient and effective health systems (2).

Studies have reported the potential of non-pharmaceutical (NP) population-based strategies to reduce the incidence of diabetes and related complications as well as cardiovascular disease risk factors (7), but few studies have been conducted in LMICs. NP diabetes strategies could include fiscal policies, legislative changes in - but not limited to trade and agriculture, health promotion activities or changes to physical environments that can influence modifiable risk factors, for example, physical activity and dietary patterns. The introduction or increase of sugar-sweetened beverage taxes in Mexico (8) and India (9), were associated with significant reductions in consumption levels, consequently delaying obesity and diabetes incidence in the respective populations. Evidence on the effect of NP diabetes interventions among LMIC populations can contribute to the prioritization of such interventions to curtail the increasing burden of diabetes.

Real-time large scale randomised control trials and cohort studies can help to generate evidence of the economic and health effects of NP diabetes interventions (10), but their application can be challenging from an ethical, implementation time and cost perspective. Ethical issues, including - but not limited to - delaying life-saving intervention in human subjects, could constitute a breach of duty of care; consequently, ethics committees may deny such studies approval. In addition, large scale randomised control trials and cohort studies are associated with high implementation costs that LMICs may not be able to afford, which could explain the limitation of these studies in lower-resource settings.

DAMs overcome these challenges by using mathematical and logical relationships to abstract real-world phenomena for investigation and simulation. DAMs use equation-based and computational simulation models to describe abstract versions of real-world systems. DAMs are most useful where the lack of data due to a rare event, legal circumstances, time, technical, ethics and funds prevent real-live studies. These methods enable comparatively cheap, convenient, and risk-free experiments that are impossible in reality (10). In addition, they offer an opportunity to perform "what-if" scenarios to predict and explore systems' responses to emergencies and extreme conditions.

This study focuses on the application of five types of DAMs: systems dynamic, agent-based models, microsimulations, discrete event simulations and Markov models, hereafter refined to as DAMs, in NP diabetes intervention. Each approach has specific assumptions and structure, highlighted in Table 1. Multiple factors determine the choice of DAMs, e.g., study problem and goal, system processes, data availability and aggregation level, and analysis unit. 
Table 1

Characteristics of decision analytical models

\begin{tabular}{|c|c|c|c|c|c|}
\hline $\begin{array}{l}\text { Distinguishing } \\
\text { features }\end{array}$ & $\begin{array}{l}\text { Markov Cohort } \\
\text { models }\end{array}$ & SD & DES & $\begin{array}{l}\text { Micro- } \\
\text { simulation }\end{array}$ & $\mathrm{ABM}$ \\
\hline $\begin{array}{l}\text { Elements of system } \\
\text { structure }\end{array}$ & $\begin{array}{l}\text { Decision nodes, } \\
\text { chance nodes, } \\
\text { pathways }\end{array}$ & $\begin{array}{l}\text { Stocks and } \\
\text { flows }\end{array}$ & $\begin{array}{l}\text { Work, } \\
\text { resources, } \\
\text { route }\end{array}$ & $\begin{array}{l}\text { Entities and } \\
\text { environment }\end{array}$ & $\begin{array}{l}\text { Entities and } \\
\text { environment }\end{array}$ \\
\hline $\begin{array}{l}\text { Nature of system } \\
\text { structure }\end{array}$ & Fixed over time & $\begin{array}{l}\text { Fixed over } \\
\text { time }\end{array}$ & $\begin{array}{l}\text { Fixed over } \\
\text { time }\end{array}$ & $\begin{array}{l}\text { Changes with } \\
\text { time }\end{array}$ & Changes with time \\
\hline $\begin{array}{l}\text { Modelling } \\
\text { perspective/ } \\
\text { approach }\end{array}$ & $\begin{array}{l}\text { Macro-level; } \\
\text { uses details of } \\
\text { a group } \\
\text { average }\end{array}$ & $\begin{array}{l}\text { Macro-level; } \\
\text { does not } \\
\text { model micro- } \\
\text { level details }\end{array}$ & $\begin{array}{l}\text { Micro-level; } \\
\text { passive } \\
\text { entities } \\
\text { move } \\
\text { through a } \\
\text { queueing } \\
\text { system }\end{array}$ & $\begin{array}{l}\text { Micro, meso or } \\
\text { macro-level; } \\
\text { passive } \\
\text { entities }\end{array}$ & $\begin{array}{l}\text { Micro, meso or } \\
\text { macro-level; } \\
\text { autonomous entities. }\end{array}$ \\
\hline Entities & $\begin{array}{l}\text { Homo-geneous } \\
\text { (group average) }\end{array}$ & Homogeneous & $\begin{array}{l}\text { Homo- } \\
\text { geneous }\end{array}$ & Heterogeneous & Heterogeneous \\
\hline $\begin{array}{l}\text { How time is usually } \\
\text { modelled }\end{array}$ & Discrete & Continuous & Discrete & Discrete & Discrete \\
\hline $\begin{array}{l}\text { How experiments } \\
\text { are usually performed }\end{array}$ & $\begin{array}{l}\text { Experiment by } \\
\text { changing } \\
\text { transition } \\
\text { probabilities }\end{array}$ & $\begin{array}{l}\text { Experiment by } \\
\text { changing } \\
\text { flows }\end{array}$ & $\begin{array}{l}\text { Experiment } \\
\text { by } \\
\text { changing } \\
\text { processes, } \\
\text { e.g., } \\
\text { schedules, } \\
\text { and work- } \\
\text { route }\end{array}$ & $\begin{array}{l}\text { Experiment by } \\
\text { changing. } \\
\text { entities' } \\
\text { environment, } \\
\text { e.g., key model } \\
\text { parameters } \\
\text { and input data }\end{array}$ & $\begin{array}{l}\text { Experiment by } \\
\text { changing } \\
\text { agents' behaviour } \\
\text { rules }\end{array}$ \\
\hline $\begin{array}{l}\text { What causes } \\
\text { changes in the } \\
\text { system behaviour }\end{array}$ & $\begin{array}{l}\text { Transition } \\
\text { probabilities }\end{array}$ & $\begin{array}{l}\text { Feedback } \\
\text { loops }\end{array}$ & $\begin{array}{l}\text { Delays and } \\
\text { the } \\
\text { occurrence } \\
\text { of sudden } \\
\text { events }\end{array}$ & $\begin{array}{l}\text { Interactions } \\
\text { and individual } \\
\text { characteristics }\end{array}$ & $\begin{array}{l}\text { Interactions and } \\
\text { agents' characteristic } \\
\text { and behaviour }\end{array}$ \\
\hline
\end{tabular}

There are few reviews on the application of DAMs to study NP diabetes interventions. Waugh et al. appraised literature (up to June 2005) on the long-term cost-effectiveness of NP intervention for preventing diabetes in at-risk populations. Gillett (11) updated Waugh et al.'s study to include additional studies published until August 2006 and in 2014, Watson et al. (12) published a similar review on NP interventions for preventing type 2 diabetes in at risk populations.. Yi et al. (13) appraised decision analytical models for evaluating type 2 diabetes interventions in general, not necessarily NP strategies. Recently, Dadwani and Laiteerapong (14) published an overview of economic simulation models to support type 2 diabetes management. These studies are like our study, reporting on applying economic models to support decisions in diabetes care. However, our study differs from all three studies such that we focus on DAMs application in LMIC populations, whereas the three studies are general. Dadwani and Laiteerapong, for instance, drew heavily on models, most of which are from HICs, presented at the Mount Hood Diabetes Challenge, a US-based network of diabetes modellers (15).

Specifically, we conducted this systematic review to investigate how DAMs have been applied to investigate NP policy interventions in LMICs, what gaps exist and how to advance their adoption to diabetes research in LMICs. In subsequent sections of this paper, we overview the five selected DAMs and then detail the methods applied in this study. The study findings, discussions and implications for research and policy are presented after that. 


\subsection{Decision Analysis models}

\section{Markov Models}

There are different Markov modelling approaches, e.g., Markov cohort model, Monte Carlo, and fundamental matrix. Monte Carlo uses probabilities and random numbers to simulate the pathway for several persons starting at a particular state. In a fundamental matrix, transition probabilities and utilities/cost associated with all states remain constant; hence expected utility/cost could be calculated with a matrix (16). This study focuses on Markov cohort models as they are commonly used in healthcare decision analysis. Markov cohort models represent the pathway of an average person from a population with similar characteristics rather than representing individual-level variability. Probabilities are assigned to events, or a percentage of the modelled cohort expected to experience particular event(s) to model transition between states. The consequences of being in a state, also called utilities or sometimes cost, are assigned to each state and time is modelled in cycles-equal time intervals accumulating to the overall time horizon considered for analysis (16). At initialization, the hypothetical population is distributed among starting states, e.g., controlled diabetes and uncontrolled diabetes and during the simulation, individuals in a particular state are divided into other states by transition probabilities resulting in a new distribution for the next cycle (16). The assumption of the "memoryless" property in Markov models restricts their application. This assumption means that transition to another state is independent of the previous states (10), which would be a simplification for diabetes where progression to another diabetes state is dependent on the previous state.

\section{System Dynamic Simulation}

SD was introduced in the 1950s to improve understanding of industrial operations using systems' processes and feedbacks loops to investigate the complex interaction and effect of structure, policies, and time delays on organisational success (17). SD is a top-down approach to analysing complex systems through buildups and feedback, usually displayed in causal loops diagrams, to determine system structure and behaviour. In a top-down approach, a group of entities' behaviour is assumed from the onset and then modelled 'as a whole' as opposed to bottom-up approaches, where group behaviour emerges from individual-level interactions (17). A causal loop diagram (collection of a system's feedback loops) is a visual representation of system structure and a qualitative assessment of system behaviour. Causal loops are transformed into a stock-flow diagram to quantitatively determine the net effect of feedback loops on system behaviour. Stocks (buildups of flow rates due to difference in inflows and outflow) and flows (quantities added or subtracted from stock) are building blocks that describe a system's state at a time. SD assumes continuous variables and models in continuous time (17).

\section{Discrete-event Simulation}

DES focuses on changes in a system state triggered by the succession of distinct events over time. Thus, DES is built on queues/queueing systems. Entities are static or dynamic objects, explicitly defined and managed through process listing -allocating them to resources that perform activities or provide services (18). DES comprises these concepts: work items, resources, routing, buffer, scheduling, sequencing, and performance (18). Work items represent individuals/items who enter the modelled system to seek services, e.g., diabetes patients (work) accessing outpatient care (services/activities). Resources are materials or human resources required for producing services. In the case of the preceding example, healthcare providers and medical equipment are resources. Healthcare resources are required for each diabetes patient (work item) seeking service(s), and services are delivered in order. The collection of services and the ordering of their performance is termed routing. Buffer is a finite or infinite list of works pending services. Scheduling 
describes patterns of resource availability, e.g., the number of doctors on a roster per month. When a queue/waiting list is countless, sequencing describes how limited resources provide services, e.g., using rules such as first-come-first-service and elderly persons first. DES can model open- or closed-loop systems. In open-loop systems, work emanates from outside the system, and their arrival time is unknown and uncontrolled by the modelled system. The opposite is true for closed-loop systems (18).

\section{Microsimulation Modeling}

Microsimulation models from an individual level using a bottom-up approach. Microsimulation modelling (MSM) is like Agent-Based Modelling (ABM) in that both techniques use a bottom-up approach to model interactions and simulate transitions between states (19). When MSM is run, individual entities are run through mechanistic processes such as a diabetes progression pathway. Entities in MSM and ABM could be heterogeneous with distinct characteristics, and in both modelling approaches, individual entities can interact (19). MSM can represent entities' behaviour by abstracting from a pool of behaviour, but the entities themselves cannot make autonomous decisions.

\section{Agent-Based Modeling}

ABM is a bottom-up modelling approach characterised by system behaviour and patterns emerging from interactive and autonomous agents' decisions. Typically, an ABM system consists of the environment, agents, and interactions among agents and between agents and the environment. Agents can be single or grouped autonomous and heterogeneous entities, e.g., individuals, communities, countries, whose behaviours are defined by rules and commands (20). Thus, ABM can abstract reality from micro-, mezzo- or macro-level, depending on the study problem. A transition between states is modelled from a bottom-up approach using rules, inferences, and probabilities (20). Unlike MSM, where aggregation of individual characteristics amounts to the population characteristic, individual-level attributes may not sum up to the population/system-level features in ABM since some characteristics/behaviours emerge from non-linear interactions between autonomous agents and among entities.

There are currently diverse views on the definition of ABM and no clear distinction between MSM and ABM in the modelling literature. There seems to be a consensus that both modelling approaches are similar in modelling bottom-up, micro-level, and multiple agents. However, it is unclear how ABM agents differ from MSM agents regarding their features and capabilities. Macal (21) identifies four definitions of ABM to consolidate the literature on ABM. Briefly and in no order, definition 1) emphasizes individual agents with different characteristics, 2) autonomous individual agents who can react to environmental stimuli, 3) individual agents can interact among themselves and with their environment and 4) autonomous and interactive individual agents learn and adapt to changes in their environment during simulation. In the context of this review, we consider ABM as models with heterogeneous and autonomous/intelligent agents who can interact with other agents and their environment. Table 1 summaries the main difference among the DAMs considered in this study.

\section{Hybrid Simulation Designs}

Hybrid models combine multiple modelling methods to describe complex systems. For example, combining ABM and SD gives both a bottom-up and top-down paradigm for simulating complex adaptive systems. Morgan et al. (22) and Swinerd and Naught (23) proposed mixed-method designs for hybridising DES and SD in particular (highlighted in Table 2) but could be used to combine other models. 


\begin{tabular}{|c|c|c|}
\hline $\begin{array}{l}\text { Swinerd and } \\
\text { Naught } \\
\text { hybrid model } \\
\text { design }\end{array}$ & Model Description/Explanation & $\begin{array}{l}\text { Morgan et } \\
\text { al. hybrid } \\
\text { model } \\
\text { designs }\end{array}$ \\
\hline \multirow[t]{7}{*}{ Integrated } & $\begin{array}{l}\text { A primary model is used as the base model, and then elements of a second model are } \\
\text { used to enrich the primary model. The model is built as a single unit, and the problem } \\
\text { dictates the need to incorporate elements of a second model. }\end{array}$ & \multirow[t]{5}{*}{ Enrichment } \\
\hline & $\begin{array}{l}\text { With this description, Swinerd and Naught identify two forms of SD and ABM hybrid } \\
\text { models designs: }\end{array}$ & \\
\hline & $\begin{array}{l}\text { 1. Rich internally structured agent: SD model built within an ABM } \\
\text { agent. E.g., Schieritz and Grobler [24] }\end{array}$ & \\
\hline & $\begin{array}{l}\text { 2. Stock agent: a component in SD is used to influence an aggregate parameter in } \\
\text { ABM. }\end{array}$ & \\
\hline & E.g., Verburg and Overmars [25] & \\
\hline & $\begin{array}{l}\text { Elements from two or more modelling approaches are combined and to form a new } \\
\text { model. Interaction between the two models occurs at a fixed time step. }\end{array}$ & \multirow[t]{2}{*}{ Integration } \\
\hline & E.g., Chaim and Streit [26] & \\
\hline Interfaced & $\begin{array}{l}\text { Two or more modelling approaches from different paradigms are combined while } \\
\text { relaxing paradigm restrictions. For instance, an ABM aggregate measure is used to } \\
\text { influence parameter(s) in SD. E.g., Dubiel and Tsimhoni [27] }\end{array}$ & Interaction \\
\hline \multirow[t]{3}{*}{ Sequential } & $\begin{array}{l}\text { A first modelling approach informs a second modelling approach; approaches } \\
\text { complement each other. Both models run separately, and information is exchanged } \\
\text { between them in consecutive runs. }\end{array}$ & \multirow[t]{2}{*}{ Sequential } \\
\hline & E.g., Schiertz and Milling [28] & \\
\hline & $\begin{array}{l}\text { Multiple modelling approaches produce two potential representations of the same } \\
\text { system, which then allows for comparison. }\end{array}$ & Parallel \\
\hline
\end{tabular}

\subsection{Methods}

This study reviews the application of DAMs to investigate NP diabetes interventions in LMICs with the aim of finding insights to advance the adoption of these methods to NP diabetes interventions. The study was designed and presented using guidelines in the Preferred Reporting Items for Systematic Reviews and Meta-Analyses (PRISMA)(24)

\section{Information sources and search strategies}

A combination of search terms for diabetes and the four modelling approaches (indicated below), identified in the first step, was used to search titles and abstracts of papers in PubMed and Cochrane databases from 1st January 2000 to 31st December 2020. We limited the results to peer-reviewed articles published in English.

- "diabetes" OR "type 1 diabetes" OR "type 2 diabetes"

AND

- “agent-based” OR “system dynamic” OR “discrete event” OR “microsimulation” OR “Markov model” 


\section{Eligibility criteria}

We included studies that meet the following criteria: 1) use any of the four DAMs, 2) examined NP interventions among persons living with type 1 or 2 diabetes or at risk of type 2 diabetes, 3) conducted the study in LMICs population per World Bank 2020 classification.

\section{Exclusion criteria}

Studies were excluded where 1) they do not report intervention effects on diabetes prevalence, diabetes incidence, treatment cost or treatment outcome as part of their primary outcomes were excluded, 2) diabetes control is secondary to a primary disease/medical condition, e.g., preventing diabetes in people with schizophrenia, because in such studies, the model is designed with a particular focus on the primary disease and 3) they focus on pharmaceutical interventions, and the pathological disposition of diabetes. Studies were excluded where the data, i.e., diabetes prevalence, obesity and blood glucose distribution-used to initialize the modelled population, were from developed countries. Diabetes prevalence and risk is higher in most developed countries, therefore using data from such countries would likely misrepresent the disease burden in LMIC. All qualitative studies, literature reviews, abstract only, non-English written papers and methodological papers were excluded. For instance, we excluded Kazemian et al.'s study (25) titled "development and validation of PREDICT-DM: a new microsimulation model to project and evaluate complications and treatment of type 2 diabetes mellitus" because the paper focused on the modelling process, i.e., the design, development and validation of the model for the US population.

\section{Data Collection Process}

We used a data extraction tool, which contained relevant information needed to answer the research question, to collect data from selected articles. We then summarised data under categories using Nvivo 12.0 and presented the summary in an excel format. The summarised data from selected articles are in supplementary materials.

\section{Data Items}

Pieces of information were extracted from the selected articles and organised under themes to answer the study questions. We collected and organised data under five themes: "study details", which included data items such as author(s), title, publication date and place; "diabetes details" consisting of the following data items: the type and clinical stage of diabetes modelled, interventions and outcomes reported. "Model design" included model type, model parameterisation and calibration, uncertainty analysis and validation. "Limitations" gathered information on study limitations reported in reviewed publications, and "economic evaluation" gathered details on the type of evaluation conducted, perspective adopted, interventions assessed, and outcomes reported.

\subsection{Results}

\section{Study selection}

Figure 1 highlights the process of article identification, screening and selection. Our initial search resulted in 405 articles, and no relevant article was retrieved from searching the reference list of selected articles and other sources. Overall, 11 studies were included in the review. Details of reviewed studies are in additional file 1. 


\section{Country and year of Research}

Five studies (38\%) reported on simulations describing Chinese sub-population only (26-30). Two studies (15\%) modelled the Indian population $((9,31)$ and two the Palestinian people $(32,33)$. One publication each $(8 \%$ each) modelled populations in Brazil (34), South Africa (35), and Iran (36). Additionally, one study represented five middleincome countries: China, India, Mexico, and South Africa (37). Studies were published between 2013 and 2020, with the highest number of publications (three) occurring in 2019.

\section{The type and diabetes progression stage modelled.}

Nine studies $(69 \%)(9,27-33,36)$ modelled adults at risk of diabetes and undiagnosed diabetes; one of the nine studies specifically looked at persons with impaired glucose tolerance (IGT)(30). Five studies $(26,29,31,34,37)$ modelled persons with diagnosed type 2 diabetes under treatment; no study modelled individuals with type 1 diabetes. One study (29) examined overweight and obesity in persons with diabetes.

\section{Outcomes reported.}

This review grouped studies based on two outcome categories: one that reports health outcomes only and another that report health outcomes plus economic outcomes. Seven studies $(54 \%)(27,29,30,34,36,37)$ looked at both health outcomes (e.g., diabetes prevalence, incidence, the onset of complications and deaths averted) and economic outcomes (e.g., cost and cost savings). The remaining six studies (46\%) assessed only health outcomes $(9,26,28,31-33)$.

\section{Interventions modelled/strategies studied.}

One study investigated an intervention for prevention and control purposes (27). This study examined screening for IGT and diabetes, dietary and physical activity interventions in at-risk populations. Six studies (46\%) investigated control interventions, of which two accessed screening strategies $(31,34)$, two compared treatment approaches/ guidelines (35, $37)$ and two accessed the implementation of comprehensive health management programmes $(26,29)$. All control interventions modelled adults with type 2 diabetes. An additional three studies examined preventive strategies, including increasing food taxes, (9) delivery of food aid (33) and spreading information about healthy lifestyle via short messaging services (30). Three other studies modelled the effect of obesity reduction (32), dairy food consumption (36) and healthy lifestyle behaviours (28), but these studies do not describe the specification of the intervention that would reduce obesity, increase dairy food consumption and promote a healthy lifestyle and therefore we could not classify such interventions as preventive or control. For instance, Abu-Rmeileh et al. (32) assume a 5\%, 10\%, 15\% and 35\% reduction in obesity prevalence and model the outcome of such reductions on diabetes prevalence in Palestine, but do not describe measures to be taken to achieve the reduction. Additionally, all studies, except one' examined non-fiscal policy intervention, i.e., Basu et al. (9) study of effect of increasing sugar-sweetened beverage taxes on obesity and diabetes incidence and complications in India.

\section{Decision model type}

Markov models and microsimulation models (6 studies each) were the most used modelling approaches as shown Fig. 2. Between 2000 and 2020, only one study (28) used ABM to examine lifestyle intervention for diabetes prevention in China. No study was found that used DES and SD. The review found no study that combined a Markov model, SD, DES, microsimulation or ABM. 


\section{Benefits of decision modelling.}

Only two studies $(15 \%)$ indicated the benefits of using DAMs $(26,30)$. Both studies indicated time, cost, ethical considerations and non-practicality of conducting long-term clinical trials as justification. Another explanation provided is the complexity of diabetes. The disease progresses gradually over a long time, and it is associated with several complications and other diseases that could be difficult to represent in a real-world experiment (26).

Seven studies discussed the benefits of using the specific modelling approach used. Three studies mentioned that the benefit of microsimulation over Markov models was mainly to represent complex relationships, individual-level dynamics, and histories $(31,35,37)$ Markov models assume individuals have the same characteristics and that transition to a health state is independent of previous health states, which does not represent the actual progression of diabetes. For instance, individuals usually transition from impaired glucose levels to prediabetes and then fully blown diabetes. These assumptions limited Markov models' use for modelling diabetes. One study (28) that investigated how individual-level factors influence public health outcomes found ABM beneficial in capturing interactions and feedback between individual-level behaviour and population-level parameters.

\section{Software}

All studies indicated the software used to implement models except for one study (28) that applied ABM. Four studies used TreeAge software to implement Markov models and an additional four used R software to implement microsimulation. MATLAB was used to implement microsimulation (9) and Markov models (26). One study used Microsoft Excel to implement a Markov model (32).

\section{Uncertainty analysis}

Uncertainty analysis examines the accuracy of model outcomes and how model outcome changes due to variations in model parameters, structure or assumptions (38). Modellers may perform first-order, second-order or structural uncertainty analysis to investigate uncertainty. The former investigates uncertainty surrounding outcomes for individuals with the same characteristics and cannot be conducted in deterministic models. Second-order examines uncertainty around model parameters and structural investigates other uncertainties that do not fit directly into parameters, methodological or heterogeneity (39). Six studies (46\%) reported performing first-order uncertainties $(9,31,33,35-37)$.

Techniques for investigating second-order uncertainty are one-way, multiway/threshold and probabilistic sensitivity analysis (PSA) (39). In a one-way sensitivity analysis, a single parameter or assumption is varied at a time, whereas in multiway, parameters or assumptions are varied simultaneously to the highest or lowest values to generate a best- or worst-case scenario; both methods are deterministic. In PSA, a model's parameters are sampled from pre-specified distributions. The outcome of PSA is an interval within which model outcomes could fall. Figure 3 shows the distribution of techniques studies used in second-order uncertainty analysis. All reviewed studies except one (26) indicated the methods used to estimate second-order uncertainty. Five studies (38\%) used several methods; four of the five studies used one-way sensitivity analyses and PSA $(9,31,34,37)$, and one used a one-way sensitivity analysis and a multiway analysis (37). Seven studies (54\%) used a single method: three each used one-way only (34-36) and probabilistic only $(33,35,36)$ and one used multiway only (32). PSA/one-way combined method is consistently used across publication years, although one-way seems popular in recent (2018-2019) studies.

\section{Validation/confidence building}

Page 10/22 
Validation is the process of comparing model components, e.g., structure, input, outcome and assumptions, with reality to increase confidence in the model outcomes. Validation techniques include face (expert assess model behaviour and processes), internal/verification (check coding accuracy), cross (compare model outputs with outputs of similar models), external (compare model output with actual data) and predictive validity (compare model output with prospectively observed data). Multiple techniques can be used to increase confidence in models.

Almost half of the reviewed studies (5 studies, 45\%) do not report model validation procedures. Model users and consumers of model results/outputs may have less confidence in unvalidated models and are less likely to use such models or their outcomes (40). Six studies (46\%) mentioned validating their models, of which four conducted external validity using historical data from national surveys and literature review $(9,31,32,34)$. The remaining two studies used a comprehensive validation approach to increase the robustness of their models $(28,36)$. Both studies combined all four validation techniques: 1) face validity through expert consultation, 2) internal validity through sensitivity analysis and manually checking codes for error, 3 ) cross validity via comparing model outputs to outputs of similar published models, and 4) external validity using actual data from national/international surveys registers.

\section{Data source, parameter estimation and calibration}

Data may be unavailable or scattered in different sources and forms that is not readily usable in a model, requiring modellers to combine or transform available data through mathematical methods to estimate and calibrate model parameters. Reviewed studies obtained data to parameterized models from plausible assumptions, previous simulation studies, published cohort studies and data recorded in clinical trials, national surveys and registers. All studies reported data limitation as a challenge to model building. LMICs suffer data limitations, and where data is available, it is often of poor quality (41). Except for one study (26) which used primary data from diabetes preventions program, studies reported using mixed-effects meta-regression, inverse-variance methods, validated hazard calculation method and validated equations from the United Kingdom Prospective Diabetes Study, WHO and International Society of Hypertension equations, and Monte Carlo Markov Chain to parameterized and calibrate models.

\section{Type of Evaluation (Health and Economic)}

Economic evaluation can produce evidence of the cost and the effect of alternative interventions to support decisions on resource allocation. Among the reviewed studies, four reported on health effects only $(9,26,28,32)$, and two reported on cost/economic outcomes only $(31,36)$ from a health system perspective. Seven studies $(54 \%)$, whose details are presented in Table 3, included evidence of both cost and health outcomes. For instance, Liu et al. (27) examined the cost of screening and lifestyle interventions from a societal perspective and the resulting health effects, including life-years remaining, quality-adjusted life years (QALYs) and incremental QALYs. 
Table 3

Details on studies that include economic analysis

\begin{tabular}{|c|c|c|c|c|c|}
\hline Authors & Model Type & $\begin{array}{l}\text { Target } \\
\text { population }\end{array}$ & $\begin{array}{l}\text { Intervention: } \\
\text { alternatives }\end{array}$ & Perspective & $\begin{array}{l}\text { Uncertainty analysis of } \\
\text { cost parameters }\end{array}$ \\
\hline $\begin{array}{l}\text { Basu et } \\
\text { al. [9] }\end{array}$ & Microsimulation & $\begin{array}{l}\text { Adults with type } \\
2 \text { diabetes }\end{array}$ & $\begin{array}{l}\text { Prescribing } \\
\text { Strategies to: } \\
\text { (1) achieve targeted } \\
\text { levels of biomarkers } \\
\text { (2) reduce risk of } \\
\text { complications }\end{array}$ & $\begin{array}{l}\text { Societal } \\
\text { perspective }\end{array}$ & Not stated \\
\hline $\begin{array}{l}\text { Ben et } \\
\text { al. (41) }\end{array}$ & Markov model & $\begin{array}{l}40+\text { years old } \\
\text { type } 2 \text { person } \\
\text { with diabetes } \\
\text { without diabetes } \\
\text { retinopathy }\end{array}$ & $\begin{array}{l}\text { Retinopathy Screening: } \\
\text { (1) Opportunistic } \\
\text { screening } \\
\text { (2) Deterministic } \\
\text { screening } \\
\text { (3) Deterministic plus } \\
\text { teleophthalmology }\end{array}$ & $\begin{array}{l}\text { Public } \\
\text { health } \\
\text { system's } \\
\text { perspective }\end{array}$ & $\begin{array}{l}\text { Vary cost by } 15 \% \text {, } \\
\text { adopted from previous } \\
\text { study in Brazil }\end{array}$ \\
\hline $\begin{array}{l}\text { Liu et } \\
\text { al. [32] } \\
(34)\end{array}$ & Markov model & $\begin{array}{l}\text { At-risk } \\
\text { population; } 25 \\
\text { years and above }\end{array}$ & $\begin{array}{l}\text { Diabetes screening: } \\
\text { (1) doing nothing } \\
\text { (2) one-time } \\
\text { undiagnosed and IGT } \\
\text { screening } \\
\text { (3) } 1 \text { plus diet } \\
\text { intervention } \\
\text { (4) } 1 \text { plus exercise } \\
\text { (5) } 1 \text { plus diet and } \\
\text { exercise }\end{array}$ & $\begin{array}{l}\text { Societal } \\
\text { perspective }\end{array}$ & $\begin{array}{l}\text { Increase and decrease } \\
\text { screening cost by } 20 \% \\
\text { based on assumption }\end{array}$ \\
\hline $\begin{array}{l}\text { Wang } \\
\text { et } \\
\text { al. [34] }\end{array}$ & Markov model & $\begin{array}{l}\text { Overweight and } \\
\text { obese type } 2 \\
\text { diabetes persons } \\
\text { enrolled in a } \\
\text { diabetes } \\
\text { program }\end{array}$ & $\begin{array}{l}\text { *Comprehensive } \\
\text { diabetes program: } \\
\text { (1) age groups } \\
\text { (2) Sex groups }\end{array}$ & $\begin{array}{l}\text { societal } \\
\text { perspective }\end{array}$ & $\begin{array}{l}\text { Increase or decrease } \\
\text { cost by } 10 \% \text { based on } \\
\text { assumption }\end{array}$ \\
\hline $\begin{array}{l}\text { Wong } \\
\text { et } \\
\text { al. [35] }\end{array}$ & Markov model & $\begin{array}{l}\text { Individuals with } \\
\text { IGT }\end{array}$ & $\begin{array}{l}\text { Diabetes Education: } \\
\text { (1) Diabetes } \\
\text { information spread via } \\
\text { short phone messages } \\
\text { plus usual practice } \\
\text { (2) usual practice only }\end{array}$ & $\begin{array}{l}\text { Health } \\
\text { systems } \\
\text { perspective }\end{array}$ & $\begin{array}{l}\text { Threshold analysis: } \\
\text { increased cost of one } \\
\text { intervention to reach } \\
\text { cost of the comparator } \\
\text { and then observe } \\
\text { difference in effect }\end{array}$ \\
\hline
\end{tabular}

Note: *A retrospective analysis of a comprehensive diabetes programme, there was no pre- and post-programme analysis or comparison with other interventions. **WHO PEN stands for the World Health Organisation's package of essential non-communicable disease interventions. 


\begin{tabular}{|c|c|c|c|c|c|}
\hline Authors & Model Type & $\begin{array}{l}\text { Target } \\
\text { population }\end{array}$ & $\begin{array}{l}\text { Intervention: } \\
\text { alternatives }\end{array}$ & Perspective & $\begin{array}{l}\text { Uncertainty analysis of } \\
\text { cost parameters }\end{array}$ \\
\hline $\begin{array}{l}\text { Basu et } \\
\text { al. [38] }\end{array}$ & Microsimulation & $\begin{array}{l}\text { At-risk } \\
\text { population; 20- } \\
\text { 79-year-olds }\end{array}$ & $\begin{array}{l}\text { Strategies to delivering } \\
\text { food aid: } \\
\text { (1) traditional food } \\
\text { parcel delivery, } \\
\text { (2) debit card restricted } \\
\text { to food purchase, (3) } \\
\text { cash to beneficiaries, } \\
\text { (4) food parcels with } \\
\text { fewer grains and more } \\
\text { fruits/vegetables }\end{array}$ & $\begin{array}{l}\text { Health } \\
\text { systems } \\
\text { and } \\
\text { societal } \\
\text { perspective }\end{array}$ & $\begin{array}{l}\text { Monte Carlo sampling } \\
\text { with replacement } \\
10,000 \text { times from } \\
\text { probability distribution } \\
\text { on all cost inputs and } \\
\text { estimated } 95 \% \\
\text { confidence interval }\end{array}$ \\
\hline $\begin{array}{l}\text { Basu et } \\
\text { al. (42) }\end{array}$ & Microsimulation & $\begin{array}{l}\text { Persons with } \\
\text { diabetes and } \\
\text { cardiovascular } \\
\text { diseases }\end{array}$ & $\begin{array}{l}\text { Cardiovascular } \\
\text { disease treatment } \\
\text { policies: } \\
\text { (1) Current treatment } \\
\text { levels } \\
\text { (2) **WHO PEN } \\
\text { (3) South Africa's } \\
\text { Primary Care treatment } \\
\text { guidelines }\end{array}$ & $\begin{array}{l}\text { Health } \\
\text { systems } \\
\text { and } \\
\text { societal } \\
\text { perspective }\end{array}$ & Not stated \\
\hline
\end{tabular}

\subsection{Discussion}

This study reviewed the application of DAMs, specifically Markov model, system dynamics, discrete event, microsimulation and agent-based models, to study NP diabetes intervention among LMICs populations to identify challenges in adoption and how to advance these methods for investigating NP diabetes interventions in LMICs. The study reviewed thirteen articles published between 2013 and 2020. The results show that more than two-thirds of the studies were conducted in Asian populations and in persons at risk of diabetes. Also, studies often used Markov cohort models and microsimulations models and examined non-fiscal interventions, e.g., screening and diabetes education program. Forty-five percent of studies do not report on model validation.

Most of the reviewed studies modelled persons at-risk of diabetes and undiagnosed diabetes compared to modelling persons with diagnosed diabetes. Reducing type 2 diabetes risks, e.g., physical inactivity and poor dietary behaviours will reduce the disease incidence, prevalence and demand for health resources. Additionally, individuals at risk of type 2 diabetes are also at risk of cancer, cardiovascular disease and chronic respiratory diseases. Together, these four noncommunicable diseases (NCDs) constitute a large percentage of the global NCD prevalence and mortality (42). This could explain why at-risk groups are most studied in the reviewed papers. LMICs diabetes prevalence will more than double in 2045 (1), implying an increased healthcare demand which may not be met due to health systems resource limitations. DAMs can save LMICs money and time allocated for large-scale RCTs by providing timely projections on the outcome of diabetes intervention, allowing time to intervene in the growing diabetes burden before it escalates.

Studies modelling preventive strategies do not describe the interventions that should be applied to reduce diabetes risk. For instance, assuming a percentage reduction in obesity and then modelling its effect on diabetes prevalence, as 
described in Abu-Rmeileh (32), may not be exciting to policymakers and practitioners interested in what actually causes the reduction in obesity prevalence. Moreover, these studies scarcely examine other sectoral approaches aside health, e.g., the influence of agricultural or urban development policies on diabetes prevalence. The article search strategy could bias this finding. DAMs built for HICs have been used to study the effect of multisectoral approaches for diabetes management, indicating a potential for similar analysis in LMICs. For instance, Basu et al. (43) used a microsimulation model to investigate the effect of community-support agriculture-buying in advance produce directly from farmers-on diabetes and cardiovascular diseases in the United States. Implementing multisectoral approaches means other institutions outside the health systems take on the implementation role, reducing the burden on health resources and providing deep insights across institutions, which could facilitate well-tailored preventive interventions. Considering inadequate health expenditure and less priority for NCDs, LMICs' should leverage existing structures/policies outside the health institution, e.g., school sporting activities, to manage diabetes as there is evidence of efficiencies to be gained across sectors (44). Future DAMs in LMICs should examine and compare non-health institutional policies and structures, e.g., fun clubs or cooperatives, which could influence diabetes risk distribution.

More than half of the reviewed studies compared the cost and consequence of interventions. The use of DAMs to compare costs and effects of alternative diabetes interventions is increasing but remains limited. Studies that conduct cost analysis or benefit analysis alone provide little evidence to support health resource allocation decisions because policymakers are interested in comparing alternative strategies given limited resources. Economic evaluation methods in DAM can prove the potential lifetime impact of investments, which means policymakers can account for or justify their choices. Having such evidence can contribute to policymakers prioritising diabetes interventions.

More than half of the reviewed studies modelled interventions among Asians, especially the Chinese population. In absolute numbers, China has the highest diabetes prevalence globally, which could be why diabetes modelling studies have targeted the country. However, there is a need to concentrate on countries in Africa because the disease prevalence on continent is projected to almost triple in the next two decades if current trends continue (1).

ABM is rarely applied to study diabetes interventions in LMICs, although they would help investigate some of the service delivery-related problems existing studies investigate. For instance, Chao et al.'s study (26), which used a Markov model to evaluate an 18-month diabetes programme, could have benefited from ABM. With ABM, it is possible to examine how individual behaviours, e.g., how individual dietary choices influence diabetes complications, which is not possible with Markov models.

This review found that SD and DES have not been applied to investigate diabetes interventions for LMICs despite their ability to represent macro-level parameters (e.g., socioeconomic status and health service utilisation on a national level) and queuing systems in health facilities respectively. Wang, Xue and Liu (45) identified that SD gives a whole system outlook rather than a reductionist view, and it is helpful for modelling obesity and chronic diseases due to the complexity and influence of social and health system components on chronic diseases. SD has been applied to study diabetes in HICs, and DES have been used to examine endocrine and metabolic-related health conditions. For instance, Chen et al. (46) used SD to analyse obesity trends in the US and the potential effect of socio-economic interventions. They found SD useful for representing national-level factors, e.g., body weight distribution, income and employment distribution, changes in parameters over time and the implication of such changes in obesity and diabetes prevalence.

Furthermore, hybrid models are emerging in the healthcare literature for their benefits of harnessing the strengths of two or more modelling approaches. The study found no study that combined two DAMs. Combining approaches helps offset the limitation or weakness of some modelling methods, thereby increasing the ability of such models to represent essential details of complex systems. Researchers have demonstrated the possibility of combining ABM, DES, and SD in representing complex health systems (47). ABM and SD can complement each other where the formal captures

Page $14 / 22$ 
heterogeneity in individuals' blood glucose levels and randomness that result from treatment behaviours and interactions between individuals and health facilities. The SD components can represent dynamic feedback mechanisms at the macro-level, such as how health facility resource capacity influences population-level diabetes treatment outcomes. Viana et al. (48) combined SD and DES to study Chlamydia infection spread in Portsmouth-UK. The DES part of their model represented clinical Chlamydia service delivery processes, while the SD part modelled the disease transmission dynamics in the community.

LMICs lack the technical capacity for building these models, which could explain their rare use. Collaborations between international and local academic and research institutions could help increase modelling expertise in LMICs. Knowledge exchange initiatives, such as the Mount Hood Diabetes Challenge Network (15), which facilitates the sharing of ideas and skills among diabetes simulation modellers through workshops, hackathons and conferences, can build capacity in LMICs for advancing DAMs.

A little above half of the reviewed studies openly discussed the rationale for using a particular modelling approach to model the problem of interest. The strengths/assumptions of the different DAMs make them more suitable for modelling specific problems, which means that modellers need to rationalise their choices, but this is not always reported in publications. Usually, the choice of modelling approach depends on the nature of the problem/system to be modelled, the data available, and sometimes researchers/modellers expertise. Using guidelines for reporting on models, e.g., ODD (Overview, Design concepts, Details) protocol (20), could encourage modellers to comprehensively describe and document modelling processes. Upcoming modelling studies should report why they used specific modelling approaches and be encouraged to standard model documentation protocols.

Almost all studies mentioned the lack of sufficient data on clinical parameters in LMICs as a limitation in their study. Models may require detailed information on real-world systems and processes to represent them closely. Healthcare data sources exist in LMICs, e.g., national demographic and health surveys and World Health Organisation SAGE studies. However, the levels of detail and quality are often insufficient, making calibration particularly important in models built for LMICs. LMICs should improve the quality of routine hospital data and increase access to institutional data for research to make data for modelling building easily accessible. In the meantime, researchers should leverage calibration and data science methods to optimise the use of existing data for building DAMs to study diabetes interventions and NCDs more broadly. Modellers may choose calibration methods depending on amount of data at hand and the nature of model parameter to be estimated. For example, weighted least-square, maximum-likelihood objective functions method, and the modified Gauss-Newton optimization method are appropriate when values of model output are nonlinear to the parameters being estimated. Where there is a deterministic linear relationship between parameter to be estimated and model output value, least-square regression method is appropriate (49).

Nearly half of the reviewed publications do not report how models were validated, and few discussed how applicable their model is to other LMICs. There is no indication of whether these models were validated but not reported or whether validation was not done. Both instances could reduce policymakers and other model users' confidence in model outcomes in their representation of real-world systems. Few DAMs are validated, extensively documented and applicable to other LMICs. Building transferable DAMs for diabetes can help increase their uptake in LMICs because not all LMICs can afford the financial and technical capacity to build large diabetes models. Moving forward, modellers should produce well-documented descriptions of modelling processes, especially the validation phase, to increase model transparency and confidence in model processes and outcomes, consequently increasing model adoption.

\subsection{Conclusion}


This study reviewed the evolution and application of DAMs for investigating NP diabetes interventions in LMICs to update the disease modelling literature and provide direction for future modelling studies. The study results indicate an overall existence of few DAM studies on diabetes interventions in LMICs. ABM DES, SD and hybrid modelling approaches have rarely been used although they can save time and money spent on real-world experiences, these modelling approaches can be effective for answering questions that existing modelling studies answer and their potential to generate additional insights that Markov or MSM models may miss. Furthermore, the details and rigour attached to modelling processes, e.g., validation, calibration and uncertainty analysis, have increased over time. However, standard model documentation guideline is required to increase model replicability and transparency, consequently increasing confidence in model results. Finally, given governments' limited investment in health, modelling studies should investigate implications of non-health sector strategies, e.g., bicycling and sporting activities in schools, for diabetes control in LMICs.

\section{Abbreviations}

\begin{tabular}{ll} 
LMICs & Low- and middle-income countries \\
\hline DAMs & Decision analytical modelling approaches \\
\hline NP & Non-pharmaceutical \\
\hline ABM & Agent-based models \\
\hline DES & Discrete event simulation \\
\hline SD & System dynamics \\
\hline MSM & Microsimulation \\
\hline NCD & Non-communicable diseases \\
\hline QALY & Quality-adjusted life years \\
\hline IGT & Impaired glucose tolerance \\
\hline RCT & Randomised control trials \\
\hline HIC & High-income countries
\end{tabular}

\section{Declarations}

\section{Availability of data and materials}

All data generated or analysed during this study are included in this published article [and its supplementary information files].

\section{Ethical approval and consent to participate}

Not applicable.

\section{Consent for publication}

Not applicable 


\section{Competing interests}

All authors declare no competing interest.

\section{Funding}

This study is funded by the University of Strathclyde as part of ETT doctoral research.

\section{Authors' contributions}

All authors contributed to conceptualising the study and provided critical feedback to direct analysis and manuscript writing. ETT selected and reviewed literature, analysed data and wrote the manuscript draft.

\section{Acknowledgements}

Not applicable.

\section{References}

1. International Diabetes Federation. IDF Diabetes Atlas. Brussel, Belgium: International Diabetes Federation; 2021.

2. Verma A, Rajput R, Verma S, Balania VKB, Jangra B. Impact of lockdown in COVID 19 on glycemic control in patients with type 1 Diabetes Mellitus. Diabetes \& Metabolic Syndrome: Clinical Research \& Reviews. 2020;14(5):1213-6.

3. World Health Organisation. Global spending on health 2020: weathering the storm. Geneva: World Health Organisation; 2020.

4. Ball D, Ewen M, Laing R, Beran D. Insulin price components: case studies in six low/middle-income countries. BMJ global health. 2019;4(5):e001705.

5. Mills A. Health care systems in low-and middle-income countries. New England Journal of Medicine. 2014;370(6):552-7.

6. Godman B. Biosimilars are becoming indispensable in the management of multiple diseases although concerns still exist. Bangladesh Journal of Medical Science. 2021;20(1):5-10.

7. Merlotti C, Morabito A, Pontiroli AE. Prevention of type 2 diabetes; a systematic review and meta-analysis of different intervention strategies. Diabetes, Obesity and Metabolism. 2014;16(8):719-27.

8. Colchero MA, Rivera-Dommarco J, Popkin BM, Ng SW. In Mexico, Evidence Of Sustained Consumer Response Two Years After Implementing A Sugar-Sweetened Beverage Tax. Health Aff (Millwood). 2017;36(3):564-71.

9. Basu S, Vellakkal S, Agrawal S, Stuckler D, Popkin B, Ebrahim S. Averting obesity and type 2 diabetes in India through sugar-sweetened beverage taxation: an economic-epidemiologic modeling study. PLoS Med. 2014;11(1):e1001582.

10. Briggs A, Sculpher M, Claxton K. Decision modelling for health economic evaluation: Oup Oxford; 2006.

11. Gillett M, Royle P, Snaith A, Scotland G, Poobalan A, Imamura M, et al. Non-pharmacological interventions to reduce the risk of diabetes in people with impaired glucose regulation: a systematic review and economic evaluation. Health Technology Assessment. 2012;16(33).

12. Watson P, Preston L, Squires H, Chilcott J, Brennan A. Modelling the Economics of Type 2 Diabetes Mellitus Prevention: A Literature Review of Methods. Applied Health Economics and Health Policy. 2014;12(3):239-53. 
13. Yi Y, Philips Z, Bergman G, Burslem K. Economic models in type 2 diabetes. Current Medical Research and Opinion. 2010;26(9):2105-18.

14. Dadwani RS, Laiteerapong N. Economic Simulation Modeling in Type 2 Diabetes. Current Diabetes Reports. 2020;20:1-11.

15. Economic simulation modelling and diabetes: MT Hood Diabetes Challenge Network 2021https://www.mthooddiabeteschallenge.com. Accessed 19 May, 2021.

16. Sonnenberg FA, Beck JR. Markov models in medical decision making: a practical guide. Medical decision making. 1993;13(4):322-38.

17. Sterman JD. System Dynamics Modeling: Tools for Learning in a Complex World. California Management Review. 2001;43(4):8-25.

18. Fishman GS. Discrete-event simulation: modeling, programming, and analysis: Springer Science \& Business Media; 2013.

19. Bae JW, Paik E, Kim K, Singh K, Sajjad M. Combining microsimulation and agent-based model for micro-level population dynamics. Procedia Computer Science. 2016;80:507-17.

20. Railsback SF. Agent-based and individual-based modeling : a practical introduction. Second edition.. ed. Grimm V, editor: Princeton ; Oxford : Princeton University Press; 2019.

21. Macal CM. Everything you need to know about agent-based modelling and simulation. Journal of Simulation. 2016;10(2):144-56.

22. Morgan JS, Howick S, Belton V. A toolkit of designs for mixing discrete event simulation and system dynamics. European Journal of Operational Research. 2017;257(3):907-18.

23. Swinerd C, Mcnaught KR. Comparing a simulation model with various analytic models of the international diffusion of consumer technology. Technological Forecasting and Social Change. 2015;100:330-43.

24. Moher D, Liberati A, Tetzlaff J, Altman DG, Prisma G. Preferred reporting items for systematic reviews and metaanalyses: the PRISMA statement. PLoS medicine. 2009;6(7):e1000097.

25. Kazemian P, Wexler DJ, Fields NF, Parker RA, Zheng A, Walensky RP. Development and Validation of PREDICT-DM: A New Microsimulation Model to Project and Evaluate Complications and Treatments of Type 2 Diabetes Mellitus. Diabetes Technol Ther. 2019;21(6):344-55.

26. Chao J, Zong M, Xu H, Yu Q, Jiang L, Li Y, et al. The long-term effect of community-based health management on the elderly with type 2 diabetes by the Markov modeling. Archives of gerontology and geriatrics. 2014;59(2):353-9.

27. Liu X, Li C, Gong H, Cui Z, Fan L, Yu W, et al. An economic evaluation for prevention of diabetes mellitus in a developing country: a modelling study. BMC Public Health. 2013;13:729.

28. Luo L, Pang B, Chen J, Li Y, Xie X. Assessing the Impact of Lifestyle Interventions on Diabetes Prevention in China: A Modeling Approach. Int J Environ Res Public Health. 2019;16(10).

29. Wang H, Wang M, Wang J, Liu H, Lu R, Duan T, et al. Cost-effectiveness analysis of comprehensive intervention programs to control blood glucose in overweight and obese type 2 diabetes mellitus patients based on a real-world setting: Markov modeling. Ann Transl Med. 2019;7(22):676.

30. Wong CK, Jiao FF, Siu SC, Fung CS, Fong DY, Wong KW, et al. Cost-Effectiveness of a Short Message Service Intervention to Prevent Type 2 Diabetes from Impaired Glucose Tolerance. J Diabetes Res. 2016;2016:1219581.

31. Basu S, Millett C, Vijan S, Hayward RA, Kinra S, Ahuja R, et al. The health system and population health implications of large-scale diabetes screening in India: a microsimulation model of alternative approaches. PLoS Med.

2015;12(5):e1001827; discussion e.

32. Abu-Rmeileh NM, Husseini A, Capewell S, O'Flaherty M. Preventing type 2 diabetes among Palestinians: comparing five future policy scenarios. BMJ Open. 2013;3(12):e003558. 
33. Basu S, Yudkin JS, Berkowitz SA, Jawad M, Millett C. Reducing chronic disease through changes in food aid: A microsimulation of nutrition and cardiometabolic disease among Palestinian refugees in the Middle East. PLoS Med. 2018;15(11):e1002700.

34. Ben Â J, Neyeloff JL, de Souza CF, Rosses APO, de Araujo AL, Szortika A, et al. Cost-utility Analysis of Opportunistic and Systematic Diabetic Retinopathy Screening Strategies from the Perspective of the Brazilian Public Healthcare System. Appl Health Econ Health Policy. 2020;18(1):57-68.

35. Basu S, Wagner RG, Sewpaul R, Reddy P, Davies J. Implications of scaling up cardiovascular disease treatment in South Africa: a microsimulation and cost-effectiveness analysis. The Lancet Global health. 2019;7(2):e270-e80.

36. Javanbakht M, Jamshidi AR, Baradaran HR, Mohammadi Z, Mashayekhi A, Shokraneh F, et al. Estimation and Prediction of Avoidable Health Care Costs of Cardiovascular Diseases and Type 2 Diabetes Through Adequate Dairy Food Consumption: A Systematic Review and Micro Simulation Modeling Study. Arch Iran Med. 2018;21(5):213-22.

37. Basu S, Shankar V, Yudkin JS. Comparative effectiveness and cost-effectiveness of treat-to-target versus benefitbased tailored treatment of type 2 diabetes in low-income and middle-income countries: a modelling analysis. Lancet Diabetes Endocrinol. 2016;4(11):922-32.

38. Loucks DP, van Beek E. System sensitivity and uncertainty analysis. Water Resource Systems Planning and Management: Springer; 2017. p. 331-74.

39. Briggs AH, Weinstein MC, Fenwick EAL, Karnon J, Sculpher MJ, Paltiel AD. Model parameter estimation and uncertainty analysis: a report of the ISPOR-SMDM Modeling Good Research Practices Task Force Working Group-6. Medical decision making. 2012;32(5):722-32.

40. Tropsha A, Gramatica P, Gombar VK. The importance of being earnest: validation is the absolute essential for successful application and interpretation of QSPR models. QSAR \& Combinatorial Science. 2003;22(1):69-77.

41. Rowe AK, Kachur SP, Yoon SS, Lynch M, Slutsker L, Steketee RW. Caution is required when using health facility-based data to evaluate the health impact of malaria control efforts in Africa. Malaria journal. 2009;8(1):1-3.

42. World Health Organisation. Mid-point evaluation of the implementation of the WHO global action plan for the prevention and control of noncommunicable diseases 2013-2020 (NCD-GAP). Geneva: World Health Organization; 2020.

43. Basu S, O'Neill J, Sayer E, Petrie M, Bellin R, Berkowitz SA. Population Health Impact and Cost-Effectiveness of Community-Supported Agriculture Among Low-Income US Adults: A Microsimulation Analysis. Am J Public Health. 2020;110(1):119-26.

44. World Health Organisation. Global report on diabetes. World health Organisation; 2016.

45. Wang Y, Xue H, Liu S. Applications of systems science in biomedical research regarding obesity and noncommunicable chronic diseases: opportunities, promise, and challenges. Advances in Nutrition. 2015;6(1):88-95.

46. Chen HJ, Xue H, Liu S, Huang TTK, Wang YC, Wang Y. Obesity trend in the United States and economic intervention options to change it: a simulation study linking ecological epidemiology and system dynamics modeling. Public health. 2018;161:20-8.

47. Viana J, Ziener VM, Holhjem MS, Ponton IG, Thogersen LJ, Simonsen TB. Optimizing home hospital health service delivery in norway using a combined geographical information system, agent based, discrete event simulation model. In 2017 Winter Simulation Conference: IEEE. pp 1658-1669; 2017. p. 1658-69.

48. Viana J, Brailsford SC, Harindra V, Harper PR. Combining discrete-event simulation and system dynamics in a healthcare setting: A composite model for Chlamydia infection. European Journal of Operational Research. 2014;237(1):196-206.

49. Hill MC. Methods and guidelines for effective model calibration; with application to UCODE, a computer code for universal inverse modeling, and MODFLOWP, a computer code for inverse modeling with MODFLOW. U.S. Geological

Page $19 / 22$ 


\section{Figures}

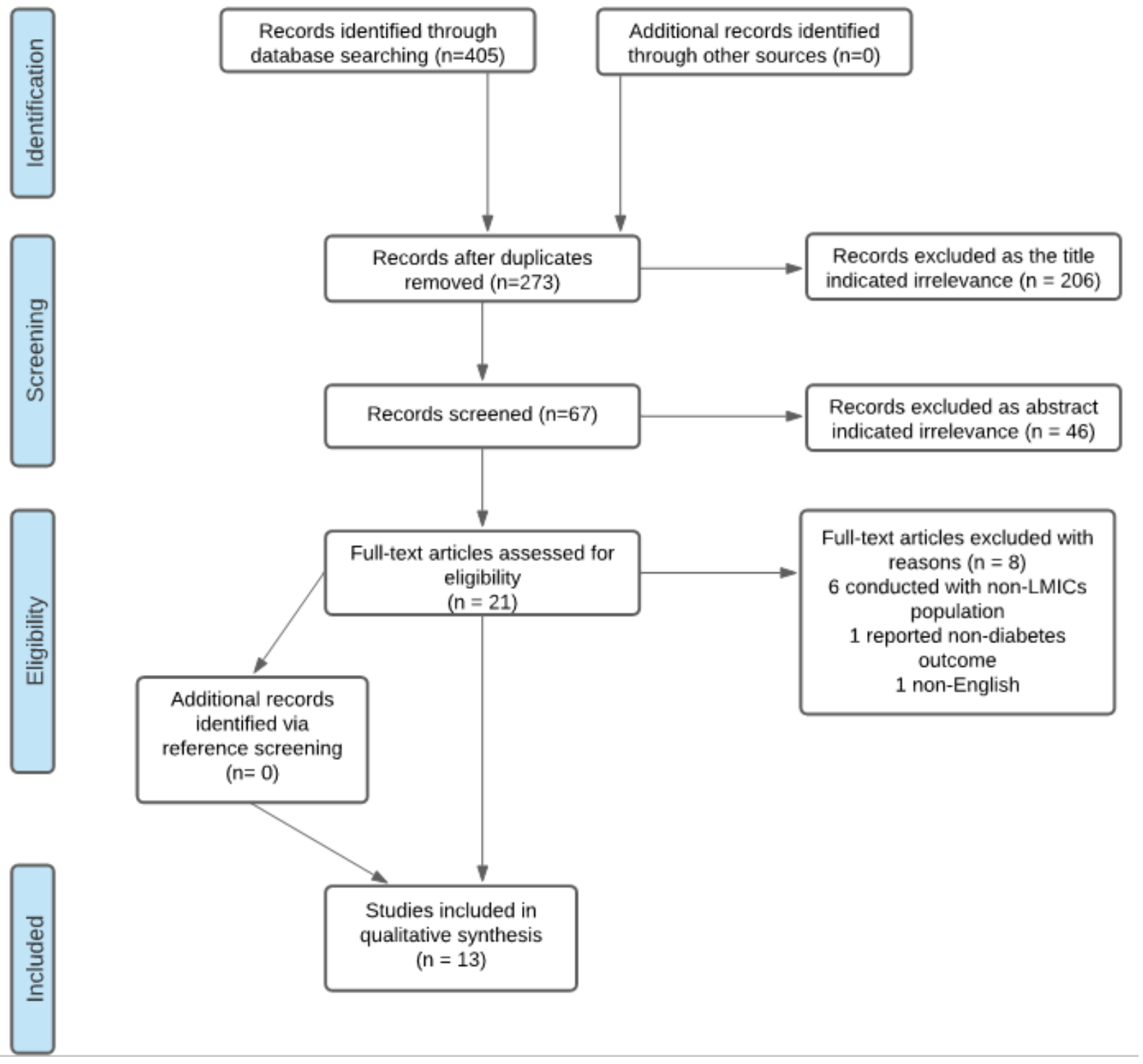

Figure 1

Article selection process 


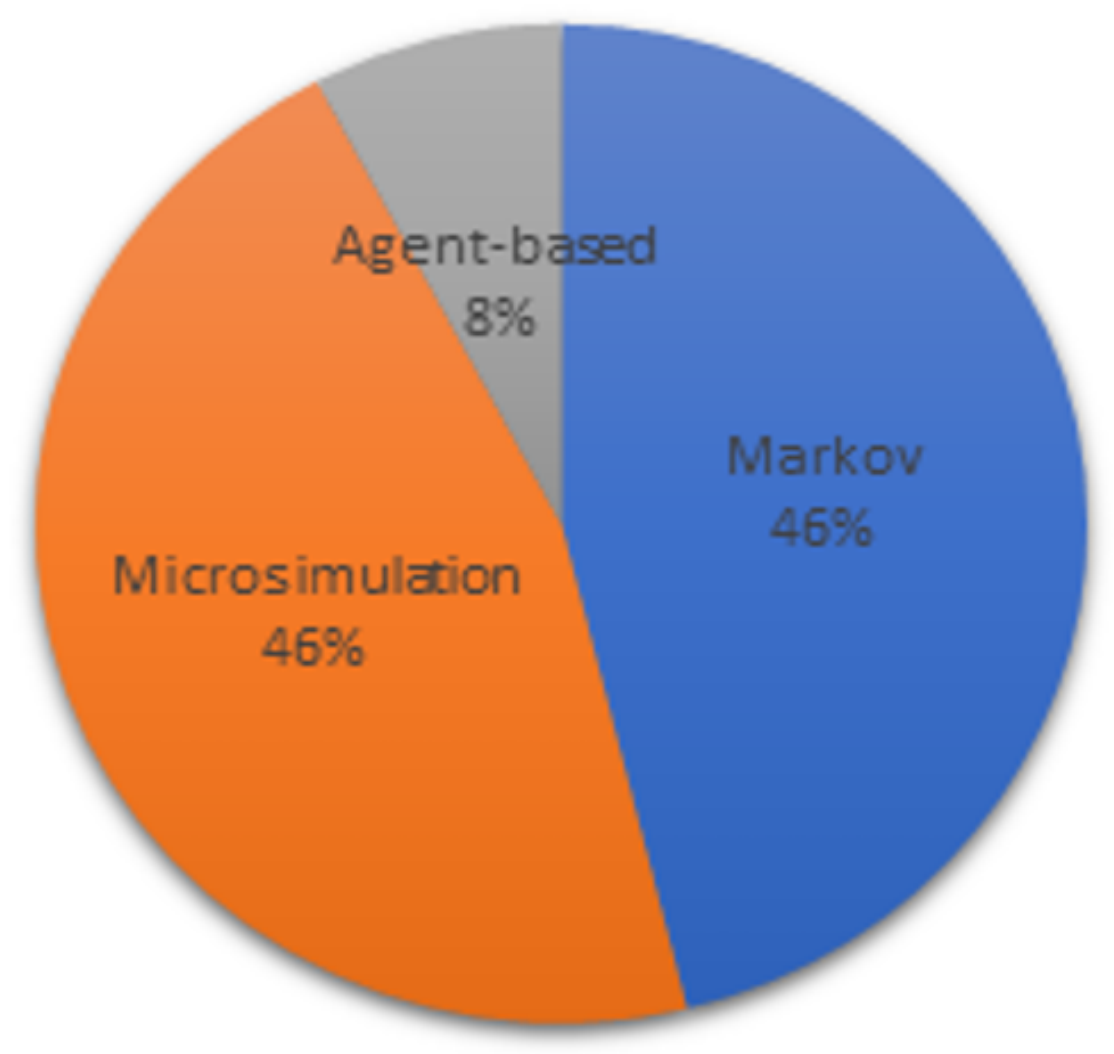

Figure 2

The distribution of modelling approaches applied in the reviewed studies

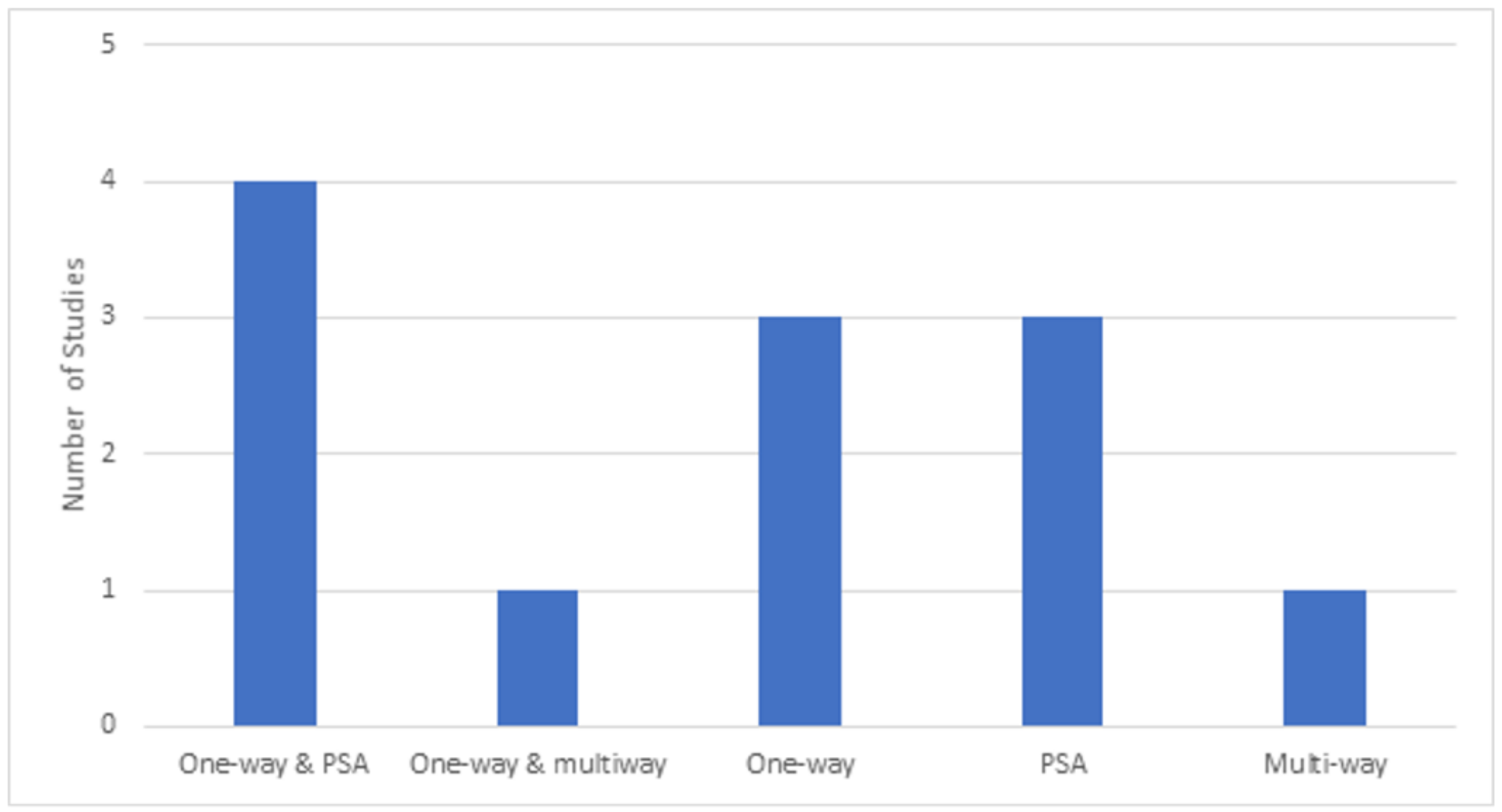

Figure 3 
Distribution of model uncertainty analysis approaches in the reviewed studies

\section{Supplementary Files}

This is a list of supplementary files associated with this preprint. Click to download.

- Additionalfile1Detailsofreviewedstudies.xlsx

- SupplimentaryInformation.docx 